\title{
TRADUCCIÓN Y FORMACIÓN DE GÉNEROS \\ la Antología de la literatura fantástica de Jorge Luis Borges, Adolfo Bioy Casares y Silvina Ocampo ${ }^{1}$
}

\author{
Walter Carlos Costa \\ UFSC/Bolsista de Pós-doutorado Sênior do CNPq
}

\begin{abstract}
RES U MEN
La Antología de la literatura fantástica es una antología singular en la historia de las literaturas hispánicas. Compilada por Jorge Luis Borges, Adolfo Bioy Casares y Silvina Ocampo, se ha transformado en un clásico del idioma aunque la mayoría de sus textos provenga de varias literaturas del Ocidente y del Oriente, sobre todo de las literaturas de lengua inglesa. La antología ha servido para firmar un género literario, que ya tenía sus raíces en el Río de la Plata del siglo XIX, en la dirección estética que defendían los tres escritores y que se oponía a la estética realista entonces dominante. Aquí se examina cómo surgió la antología, la parte que ha jugado cada uno de los antólogos y las diferencias de criterio de selección de autores extranjeros y nacionales entre sus dos ediciones: la primera de 1941 y la segunda de 1965.
\end{abstract}

\section{PALABRAS - CLAVE \\ Antología. Jorge Luis Borges. Adolfo Bioy Casares. Silvina Ocampo. Traducción.}

$E_{n}$ las letras hispanoamericanas como en las letras brasileñas se suele subestimar la labor pedagógica, la labor en colaboración y una amplia gama de labores no directamente ligadas a la labor original. Así escribir entradas para enciclopedias y diccionarios, prefacios, posfacios, solapas, contratapas y reseñas, hacer traducciones, dirigir colecciones y organizar antologías son consideradas formas subordinadas de actividad intelectual, a que uno se somete urgido por razones de orden material. Aunque en nuestra práctica profesional a menudo utilicemos esas herramientas - diccionarios, enciclopedias, reseñas, traducciones, antologías - siempre tendemos a preferir las herramientas más nobles: libros de teoría y crítica y las obras de creación en su lengua

\footnotetext{
${ }^{1}$ Querría agradecer a Silvana Serrani, con quien he estado discutiendo el tema antología en los últimos años, y a Graciela Ravetti, junto a quien hago en este momento una investigación de posdoctorado sobre la Antología de la literatura fantástica, de Jorge Luis Borges, Adolfo Bioy Casares y Silvina Ocampo y con quien he mantenido frecuentes y fructíferos diálogos.
} 
original, si es posible. Demás está decir que no todas las culturas encaran esa producción secundaria como despreciable. Algunas de ellas, como la china y la alemana, al contrario, la tratan con el respeto que merecen los medios que ayudan a preservar la memoria y dar continuidad a lo alcanzado por las generaciones anteriores, tanto del país como del mundo. Modernamente quizás ninguna cultura valore esas actividades de forma tan sistemática como la cultura inglesa y su extensión, la cultura norteamericana y las culturas de los países de habla inglesa de una manera general. Nosotros no tenemos el equivalente a instituciones tan respetables como el británico Oxford Book of Verse o la enormes antologías Norton utilizadas en la universidad norteamericana. Mucho de lo que es y produce la cultura inglesa y americana se debe a esas herramientas que se hacen y rehacen cada año y que constituyen además una fuente muy lucrativa para editoriales y autores.

Si nuestra cultura suele tener esa postura como un todo, por supuesto que no todos los intelectuales la suscriben. En Brasil tenemos el caso ejemplar de Manuel Bandeira que, junto con ser uno de los dos o tres mejores poetas nacionales, fue también un organizador incansable de antologías, historias literarias, ediciones y traductor constante. En las letras hispánicas, nadie como Jorge Luis Borges supo realizar durante toda su larga y productivísima vida intelectual esas labores.

Se puede especular sobre los factores que contribuyeron a que Borges desarrollara ese hábito, que tan buenos frutos dio a la cultura hispánica y mundial. Pudo haberlo contraído en Suiza, donde hizo su escuela secundaria, la misma Suiza donde estuvo Manuel Bandeira. Puede ser también el resultado de su temprana adicción a la lectura en esa biblioteca paterna de "infinitos libros ingleses", donde no faltarían las antologías y una variada gama de obras en colaboración.

Lo cierto es que Borges practicó la escritura y la organización de libros en colaboración con una gran variedad de personas y en especial con su gran amigo Adolfo Bioy Casares. La bibliografía de Borges, fácilmente accesible en una variedad de fuentes, entre ellas internet, indican que fue extenso el número de obras en colaboración que contaron con el aporte de Borges pero un volumen recién publicado muestra que la producción de Borges y Bioy fue muchísimo más amplia y variada de lo que se conocía hasta ahora. En 2006, la editorial Destino de Barcelona publicó un volumen de 1663 páginas y otras 16 de ilustraciones titulado simplemente Borges, firmado por Bioy Casares, con la edición al cuidado de Daniel Martino. Este libro recoge parte de las cerca de veinte mil páginas de diario de Bioy Casares, una empresa semejante a la de los célebres Cahiers de Paul Valéry y, creo, sin comparación con ninguna otra obra escrita en América Latina. Por otra parte, las 1663 páginas de Bioy que registran los diálogos casi cotidianos con su gran colaborador intelectual en los 39 años que van de 1947 a 1986, se parecen al conocido libro de Boswell sobre Samuel Johnson, que tanto Borges como Bioy admiraban plenamente. El libro de Bioy corrige y complementa las informaciones que teníamos a través sobre todo de biografías y de las propias entrevistas de Borges y nos ofrece una visión privilegiada de la colaboración intelectual de los dos, vista desde adentro. Entre otras cosas, Bioy registra más de una decena de antologías que los dos prepararon para editoriales y que nunca han sido editadas. Registra también proyectos curiosos como el de una antología pornográfica y otra de Escritores justamente olvidados. 
Sólo por ese costado, se puede decir que del arca de Borges se sacarán muchas más cosas que de la mítica arca de Fernando Pessoa.

En el libro de Bioy hay muchas referencias a antologías en general y a la Antología de la literatura fantástica, en particular. Llama la atención el siguiente diálogo ocurrido el sábado 20 de julio de 1968 entre los dos amigos:

Borges: Aun prescindiendo de sus textos argentinos, nuestra Antología fantástica es una de las obras capitales de la literatura argentina.

Bioy: También me parecen importantes, aunque en menor grado, algunos volúmenes de "El séptimo círculo": junto con la Antología, contribuyeron a enseñar a inventar y a contar argumentos (Bioy. Borges, p. 1.220).

Este diálogo, como otros en el libro, muestran claramente que Borges y Bioy tenían clara conciencia del impacto de su trabajo como antólogos en la literatura argentina.

\section{la Antología de la literatura fantástica}

La traducción suele jugar un papel central en la importación de géneros literarios, aunque su rol es a menudo más implícito que explícito. El impacto de las traducciones llevadas a cabo por la revista y por la editorial Sur ha sido subrayado por distintos estudiosos y mereció un análisis detenido de Patricia Willson en La constelación del Sur - traductores y traducciones en la literatura argentina del siglo XX, editado por Siglo XXI Argentina en 2004. La Antología de la literatura fantástica, de Jorge Luis Borges, Adolfo Bioy Casares y Silvina Ocampo, con una mayoría de textos traducidos, ha sido considerada por la crítica y por la historia literaria como una pieza clave en la formación del género fantástico en la literatura rioplatense e hispanoamericana, contribuyendo a la renovación del canon y transformando un género antes marginal en un género central en esas literaturas. El volumen de Ocampo, Bioy y Borges parece haber jugado un papel fundamental en la consolidación del género fantástico en la literatura rioplatense en un primer momento y luego en el ámbito hispanoamericano y del idioma en las décadas siguientes. Lejos de ser una iniciativa aislada, la Antología es una de las armas usadas por los autores para afirmarse como autores de primera plana dentro del sistema literario argentino junto con la colaboración en revistas, diarios y editoriales, así como la elaboración de sus respectivas obras.

El 28 de junio de 1978, cuando Borges tenía 79 años y era una celebridad mundial, Bioy registra en su diario una rara hipérbole de Borges: Borges, sobre la Antología de la literatura fantástica: "Es el mejor libro del mundo." (Bioy. Borges, p. 1.512)

$\mathrm{Al}$ parecer, en ese momento de balance de vida, Borges no hesita en considerar la obra hecha con el amigo y con la mujer del amigo como una de las mejores obras no sólo de ellos sino de la literatura.

\section{Cómo surgió la Antología}

La Antología tuvo de hecho dos versiones bastante distintas y que reflejan el estado del género y la posición de los antólogos en dos momentos importantes de la historia literaria rioplatense. La continuación examino brevemente las dos versiones de la 
Antología y propongo algunas hipótesis sobre los criterios que pueden haber presidido la selección de textos y autores.

Esta antología es tan importante que mereció un capítulo propio en el tomo 9 de la Historia crítica de la literatura argentina, organizado por Sylvia Saítta, escrito por Daniel Balderston y titulado "De la Antología de la literatura fantástica y sus alrededores". Balderston llama la atención sobre un hecho importante: la antología que circula, y que está disponible en una variedad de ediciones, corresponde a la segunda edición revista y ampliada, publicada en 1965, no a la compilada originalmente en 1940.

Balderston describe de manera precisa el surgimiento de la verdadera bomba literaria que fue la Antología de la literatura fantástica:

El 24 de diciembre de 1940 se terminó de imprimir en Buenos Aires un libro de tapas grises y letra roja en la flamante Editorial Sudamericana, inaugurando la Colección Laberinto que, señala la solapa, "ofrecerá al público de habla hispánica lo perdurable y lo viviente de las diversas disciplinas de la literatura mundial. Textos sabiamente elegidos, escrupulosas versiones de las obras extranjeras, clara y elegante tipografía, definen esta biblioteca de apasionante interés y de extraordinario valor cultural". La Antología de la literatura fantástica, de Jorge Luis Borges, Silvina Ocampo y Adolfo Bioy Casares, define un hito en la historia argentina, no por ser la primera vez que se hizo literatura fantástica en el país (esa tradición remonta por lo menos hasta Eduardo Holmberg en el siglo XIX), ni que se tradujo obras fantásticas de literaturas extranjeras, sino por el carácter didáctico - hasta evangélico- que tiene. Bioy Casares, en la postdata a la edición ampliada y revisada de 1965, habla de un "bien intencionado ardor sectario por parte de los antólogos (Balderston. De la Antología de la literatura fantástica y sus alrededores, p. 217).

El crítico uruguayo Emir Rodríguez Monegal, uno de los primeros estudiosos y biógrafos de Borges caracteriza bien lo novedoso de la iniciativa:

En Sudamericana se publicaron dos antologías, dirigidas por Borges y los Bioy, que fueron decisivas para la formación de escritores que habrían de producir una resurrección de la literatura hispanoamericana. La primera, publicada el 24 de diciembre de 1940, fue la Antología de la literatura fantástica. Es hasta hoy una de las recopilaciones más curiosas y menos ortodoxas sobre esos temas. Incluye textos del Oriente (Tsao Hsuekin, Las mil y una noches, Chuang Tzu), junto a clásicos de la literatura occidental (Petronio, Don Juan Manuel, Rabelais, Carlyle, Poe, Carroll, Maupassant, Kipling), maestros modernos y famosos (Wells, Chesterton, Kafka, Joyce), que compartían sus páginas con talentos locales (María Luisa Bombal, Borges, Santiago Dabove, Macedonio Fernández, Arturo Cancela, Pilar de Luzarreta). La antología era sumamente personal y (en el mejor sentido de esta palabra) arbitraria. El prólogo, escrito y firmado por Bioy, resume las ideas del trío sobre la literatura fantástica. (Monegal. Borges - una biografía literaria, p. 315).

Rodríguez Monegal fue también uno de los primeros a ver una analogía entre el trabajo de los antólogos y el trabajo de los escritores, señalando la concomitancia de la extraordinaria antología con el primer libro importante de Bioy Casares: "El 14 de noviembre de 1940, pocas semanas antes de que se publicara la Antología, Losada había editado La invención de Morel, del mismo Bioy Casares. Llevaba un prólogo de Borges que suponía un manifiesto sobre la literatura de lo fantástico" (Monegal. Borges - una biografía literaria, p. 317).

Un elemento importante en el análisis de la Antología de la literatura fantástica es su triple colaboración. Pero, ihasta dónde fue realmente triple la colaboración? Hay 
controversia al respecto. La triple colaboración se extendió en el mismo año a la malograda Antología de la poesía argentina, que nunca ha sido reeditada. A partir de 1941, los proyectos comunes reunirían a Borges y Bioy, y Silvina iría apartada. La fama total de Borges a partir de los años 60 y el creciente prestigio de Bioy, así como el largo eclipse sufrido por Silvina y su obra contribuyeron para firmar la idea de que la participación de ésta habría sido meramente decorativa. Para Annick Louis, sin embargo, el rol de Silvina Ocampo ha sido menospreciado por una serie de motivos externos e internos:

A pesar de que la Antología de la literatura fantástica se presenta como una compilación que realizaron Jorge Luis Borges, Silvina Ocampo y Adolfo Bioy Casares (tanto en la portada como en la página del título los nombres aparecen en ese orden), críticos y lectores han tendido a minimizar la participación de Silvina en la empresa. Frecuentemente la autoría se atribuye, sin reservas, a Borges y Bioy Casares; otras veces, la presencia de Silvina es justificada en función de las sabidas relaciones personales (esposa de Bioy, amiga de Borges), y cuando su participación no es ignorada, es reducida a una presencia puramente nominal. Puede decirse que, en cierta medida, las relaciones personales entre los compiladores sirvieron para ocultar las ideas que el volumen expresaba - y los nexos que pueden percibirse entre éstas y la producción de los tres escritores. El hecho de que el año de publicación de la Antología sea el del casamiento de Silvina y Bioy, con Borges como testigo, contribuye a acentuar este desplazamiento y a transformar la actuación de Silvina en una mera anécdota, una prueba más de los vínculos personales, un acontecimiento sin proyección literaria. Silvina fue durante un tiempo una autora secreta, para iniciados. Por otra parte, su desinterés por los debates y discusiones sobre cuestiones literarias - en tanto debates públicos, ya que en su obra pueden leerse varios debates estéticos de época -, así como el silencio acerca de su vida personal, favorecieron su permanencia en un segundo plano. (Louis. Definiendo un género: La Antología de la literatura fantástica de Silvina Ocampo, Adolfo Bioy Casares y Jorge Luis Borges, p. 1).

La misma Silvina tiene una opinión muy tajante sobre la paternidad o maternidad de la obra. Adriana Mancini, que ha estudiado en profundidad la obra de Silvina Ocampo, reproduce un curioso diálogo entre una periodista y Silvina:

Bioy Casares, Borges y Ud. publicaron la Antología de la literatura fantástica en 1940, que es la primera en el país. / S.O.: Ya lo creo, yo me entusiasmé con las antologías de cuentos de horror, cuentos policiales, y fantásticos que existían en la literatura inglesa. Había muchísimas cosas de fantasmas... y yo dije, ipor qué no hacemos una antología de cuentos fantásticos aquí, que no existe?/ V.: ¿Es decir que la idea salió un poco de Ud.? / S.O: Prefiero decir del todo (Mancini. La literatura del arte de dudar, p. 155-156, nota 38).

Borges, por su parte, ha declarado: "Este libro [Antología de la literatura fantástica] lo hicimos Bioy y yo; realmente ella ha colaborado poco" (citado por Jorge Panesi, en "Los monstruos y la risa", en Cultura y Nación, Clarín, 8 de agosto de 1994). (Mancini. La literatura del arte de dudar, p. 156, nota 38).

\section{LA PRIMERA EDICIÓN}

De hecho, tanto Silvina como Borges parecen tener razón. Ella reivindica la autoría de la idea de la antología, no de su composición, mientras que Borges no toca el tema de la idea y se concentra en el trabajo, gran parte del cual lo habrían hecho él y Bioy 
mientras que Silvina habría "colaborado poco". La idea claramente se refiere a la primera edición, mientras que el trabajo se refiere implícitamente a las dos ediciones.

Lo que dice Bioy de los 39 años de colaboración casi diaria de los dos fortalece la hipótesis de que realmente lo principal de la antología, sobre todo de la segunda edición, lo hicieron los dos. El diario de Bioy registra puntualmente la degradación progresiva de las relaciones entre Silvina y Borges que si no llegaron a una ruptura pasaron por momentos difíciles; Silvina le reprochaba a Borges, a medida que se volvía más y más famoso, su egoísmo y desinterés por ella. Bioy, por su lado, llega a quejarse de que Silvina trata de apartarlo del amigo, aunque observe también que, con el tiempo y la fama, Borges se ha vuelto menos atento con los viejos amigos, interesándose más por sí mismo que por ellos.

Antes de examinar las dos ediciones sentí una tendencia natural a creer que Silvina Ocampo, y aun Bioy, había sido sacrificado por los editores en aras de Borges, cuyo nombre vendía, y sigue vendiendo, más. Sin embargo, examinando los textos de las dos ediciones se puede concluir que gran parte del trabajo, incluso de traducción, se debe al dúo Borges-Bioy y que las ideas generales que orientan las dos ediciones, sobre todo la segunda, son sobre todo de Borges, eso sí, compartidas en su gran mayoría por Bioy y en mucho menor medida por Silvina. Llego a esta conclusión a partir de mi conocimiento de la obra y los procedimientos de Borges pero es posible que una lectura atenta de la obra de Silvina Ocampo y de Bioy cambie un poco esa percepción.

La primera edición trae 54 textos, algunos de autores repetidos, licencia típica de Borges y de Bioy. Me parecen aportes del dúo la selección de algunos de los autores ingleses cuya admiración comparten como Kipling, Olaf Stapledon, Carlyle, Chesterton, W. W. Jacobs y Max Beerbohm y el norteamericano O’Neill, así como Kafka, Maupassant (que Bioy admira más que Borges), Rabelais, Papini, el episodio de las 1001 noches y el español Don Juan Manuel. Parecen ser compartidos por los tres compiladores los autores argentinos incluidos en la primera edición como Lugones, Macedonio Fernández, Santiago Dabove, Manuel Peyrou, Arturo Cancela \& Pilar de Lusarreta y algunos ingleses como H.G. Wells, Saki y Lewis Carroll. Ya la selección de María Luisa Bombal pudo haber sido una sugerencia de Silvina. Son típicas de Borges, me parece, la selección de los chinos Tsao Hsue-Kin, Chuang Tzu y especialmente de los franceses Jean Cocteau y Léon Bloy, el latino Petronio, los etnógrafos Alexandra David-Néel, James George Frazer, el orientalista Richard Wilhelm, el místico Swedenborg y el filólogo Thomas Bailey Aldrich. Me parece, en cambio, tanto en la primera como en la segunda edición, que las falsas atribuciones son más una preferencia de Bioy que de Borges pues, como lo comprueba el diario de Bioy, contra la creencia general que el chequeo del intertexto no confirma (ver al respecto el libro de Balderston que corrige ciertas falsas atribuciones que no lo son). En todo caso, de los 54 textos de la primera edición uno solamente puede ser una falsa atribución: "Los ganadores de mañana", atribuido a un cierto Holloway Horn. Todos los demás textos son de autores verdaderos, aunque muchos muy poco conocidos y ahora, gracias a las facilidades digitales, no difícilmente encontrables. 


\section{LA SEGUNDA EDICIÓN}

Uno de los cambios más visibles es la adopción del orden alfabético, el orden de los diccionarios y de las enciclopedias; el orden, podríamos decirlo, de Borges más que de Bioy o de Silvina, esta última más ausente que presente en esta segunda entrega.

Como queda claro en el citado Borges, de Bioy Casares, la creciente colaboración entre los dos amigos tendió a poner en segundo plano la contribución de Silvina Ocampo, que parece una participación muy discreta en la segunda edición de la antología. Otro elemento a considerar, subrayado por Balderston, es que el "fervor evangélico", manifestado en el prefacio de Bioy Casares y autocriticado en la postdata de 1965 por el mismo Bioy, cedió lugar con el paso del tiempo a una actitud más distanciada, que reflejaría los cambios tanto en el sistema literario argentino como en los mismos antólogos. De hecho, para Balderston

(...) el paso por lo fantástico de Borges, Silvina Ocampo y José Bianco fue más bien breve. Sólo Bioy Casares y Cortázar tuvieron un interés duradero en esta modalidad narrativa, y aun para ellos ese interés duraría hasta la década de[e] los sesenta. (...) Por lo tanto, la reedición de 1965 marca el fin de algo que ya no practicaban los tres antólogos, y mucho menos su círculo (Balderston. De la Antología de la literatura fantástica y sus alrededores, p. 226).

Uno de los grandes cambios entre las dos ediciones es justamente el papel de los autores traducidos: en la segunda, con el género fortalecido, aumenta el número de contribuciones argentinas y de habla hispana. En la primera, de los antólogos, sólo estaba incluido Borges, en la segunda entran también Silvina Ocampo y Bioy además de un texto compilado por Borges y una de sus colaboradoras, Delia Ingenieros.

La importancia de esta antología se comprueba en diferentes niveles. Además de seguir atrayendo al cambiante público lector hispánico, es notable por dos hechos infrecuentes: por cruzar las fronteras del idioma en que nació y también por ser asunto de una historia literaria reciente. Así, la Antología ha ganado una versión británica ${ }^{2}$ y una versión italiana (con dos impresiones distintas). Es la segunda edición que es traducida, no la primera.

La segunda edición se caracteriza por un corte y varias incorporaciones. Se eliminan dos textos, uno de Cocteau y otro de la chilena María Luisa Bombal, este último quizás más afín a la estética que seguiría Silvina que a la de los otros antólogos. Cocteau sigue en la segunda edición con otro texto, pero María Luisa Bombal es suprimida en cuanto autora. En total son 77 textos en esta segunda y definitiva edición. Se agregan varios argentinos del agrado de los tres antólogos, como Juan Rodolfo Wilcock, Julio Cortázar, Manuel Peyrou, Carlos Peralta, H. A. Murena, José Bianco, así como algunos autores típicos de Borges como el japonés Akutagawa, Martin Buber y el super borgiano Sir Richard Francis Burton, que la Wikipedia borgianamente define como: "explorador, traductor, escritor, soldado, orientalista, etnólogo, lingüista, poeta e hipnotizador".

Concluyendo, cabe señalar que la Antología de la literatura fantástica se ha vuelto un curioso clásico de las literaturas hispánicas, ya que la mayoría de sus textos son traducciones, un poco a la manera de la traducción de Rubaiyat, del persa Omar Khayyam,

${ }^{2}$ BORGES; BIOY CASARES; OCAMPO. The Book of Fantasy. Introduced by Ursula K. Le Guin. 
que los ingleses incorporaron a su literatura a través de la traducción, inventiva aunque no siempre cercana al original persa, de Edward Fitzgerald.

\title{
A
}

\section{RESUMO}

A Antología de la literatura fantástica é uma antologia singular na história das literaturas hispânicas. Compilada por Jorge Luis Borges, Adolfo Bioy Casares y Silvina Ocampo, tornou-se um clássico da língua, embora a maioria de seus textos provenha de diferentes literaturas do Ocidente e do Oriente, sobretudo das literaturas de língua inglesa. A antologia serviu para consolidar um gênero literário, que já tinha suas raízes no Rio da Prata do século XIX, na direção estética defendida pelos três escritores e que se opunha à estética realista então dominante. Aqui se examina como surgiu a antologia, a parte desempenhada por cada um dos antologistas e as diferenças de critério de seleção de autores estrangeiros e nacionais entre suas duas edições: a primeira de 1941 e a segunda de 1965.

\author{
PALAVRAS - CHAVE \\ Antologia. Jorge Luis Borges. Adolfo Bioy Casares. \\ Silvina Ocampo. Tradução.
}

\section{B I B LIO O RAFÍA}

BALDERSTON, Daniel. De la Antología de la literatura fantástica y sus alrededores. In: SAÍTTA, Sylvia. Historia crítica de la literatura argentina. Buenos Aires: Emecé, 2004. p. 229-251. Tomo 9: El oficio se afirma.

BORGES, Jorge Luis; BIOY CASARES, Adolfo; OCAMPO, Silvina. Antología poética argentina. Buenos Aires: Sudamericana, 1941.

BORGES, Jorge Luis; BIOY CASARES, Adolfo; OCAMPO, Silvina (Ed). The Book of Fantasy. Introduced by Ursula K. Le Guin. London: Black Swan, 1990.

BIOY CASARES, Adolfo. Borges. Barcelona: Ediciones Destino, 2006.

LOUIS, Annick. Definiendo un género: la Antología de la literatura fantástica de Silvina Ocampo, Adolfo Bioy Casares y Jorge Luis Borges. Nueva Revista De Filología Hispánica, 49, p. 409-437, 2001.

MANCINI, Adriana. La literatura del arte de dudar. In: SAÍTTA, Sylvia. Historia crítica de la literatura argentina. Buenos Aires: Emecé, 2004. p. 229-251. Tomo 9: El oficio se afirma. MANCINI, Adriana. Silvina Ocampo: escalas de pasión. Buenos Aires: Norma, 2003.

RODRIGUÉZ MONEGAL, Emir. Borges - una biografía literaria. Trad. Homero Alsira Thesnet. México: Fondo de Cultura Económica, 1987.

WILSON, Patricia. Página impar: el lugar del traductor en el auge de la industria cultural. In: SAÍTTA, Sylvia. Historia crítica de la literatura argentina. Buenos Aires: Emecé, 2004b. Tomo 9: El oficio se afirma.

WILSON, Patricia. La constelación del Sur, traductores y traducciones en la literatura argentina del siglo XX. Buenos Aires: Siglo Veintiuno Argentina, 2004a. 